Association for Information Systems AIS Electronic Library (AISeL)

Wirtschaftsinformatik Proceedings 2001

Wirtschaftsinformatik

September 2001

\title{
Action Research: Researching with Industry
}

Glenn Stewart

Queensland University of Information Technology, g.stewart@qut.edul.au

Guy Gable

Queensland University of Information Technology, g.gable@qut.edu.au

Follow this and additional works at: http://aisel.aisnet.org/wi2001

\section{Recommended Citation}

Stewart, Glenn and Gable, Guy, "Action Research: Researching with Industry" (2001). Wirtschaftsinformatik Proceedings 2001. 69. http://aisel.aisnet.org/wi2001/69

This material is brought to you by the Wirtschaftsinformatik at AIS Electronic Library (AISeL). It has been accepted for inclusion in Wirtschaftsinformatik Proceedings 2001 by an authorized administrator of AIS Electronic Library (AISeL). For more information, please contact elibrary@aisnet.org. 
In: Buhl, Hans Ulrich, u.a. (Hg.) 2001. Information Age Economy; 5. Internationale Tagung Wirtschaftsinformatik 2001. Heidelberg: Physica-Verlag

ISBN: 3-7908-1427-X

(C) Physica-Verlag Heidelberg 2001 


\title{
Action Research: Researching with Industry
}

\author{
Glenn Stewart, Guy Gable \\ Queensland University of Information Technology
}

\begin{abstract}
This paper reviews the action research component of a three-year project set in an Information Technology Unit seeking to become a strategic partner of business. We first describe the research project and design. We then demonstrate how the project moved the participants to take charge of the research project in order to change their own culture, their individual leadership practices, and their relationships with each other and the business managers. Finally, we discuss how this tested methodology can be used in other IS Research.
\end{abstract}

Keywords: Action Research, Leadership, IT Management

\section{Introduction}

Many factors can inhibit or motivate the use of information technology (IT) to improve business processes, increase market share or change the very way in which business is conducted. Influential factors include the leadership capability of the IT executives and perceptions of the strategic value of IT held by the senior business management team. This paper reports on the conduct of a three-year research program in which we sought to improve the leadership practices of the Information Technology unit within a large public sector agency (hereafter referred to as Industry Partner). A main driver behind the study was the IT function's desire to improve its relationship with the business.

This paper first poses its questions, research design and presents its main outputs. We then show how the research contributed to the needs of the IT unit. We close by showing the application of the action research method to IS research in practice.

\section{The Research Problem and Questions}

In this study, we sought to answer the following questions: 
1). Can the leadership practices of individual IT managers be improved through the application of a minimalist intervention program? Are these changes noticeable through measures other than through established survey instruments such as the Multi-factor Leadership Questionnaire (MLQ) [BaAv97]? Do improvements in IT leadership practices translate into an improved relationship between the IT and business communities?

2). How can implicit leadership beliefs be determined? Are there any qualitative differences in the implicit leadership beliefs of business executives and IT executives? If there are, how does this difference in belief affect their relationship and the alignment of business and IT activity?

3). What is the nature of the relationship between the business and IT management communities within organisations? How can this relationship be determined? and

4). What are the current leadership practices of IT managers? How do these compare with industry norms? How do these compare with expectations of extraordinary leaders?

The answers to the questions have been published elsewhere. The purpose of this paper is to present and discuss the conduct of the study as Emancipatory Action Research.

\section{The Overarching Study Context}

We could not conduct this research in a laboratory. We needed the active participation of an industry partner. The research was grounded in an organisational setting. We secured an Australian Research Council (ARC) Collaborative Grant to undertake this research project. This 3-year project had to deliver benefits to both the industry partner and the research community. Funding was $\$ 200,000$ in cash and in kind, with 50\% each from the ARC and the Information Technology and Resource Management Unit (ITRMU) of the Industry Partner.

The ITRMU sought to: 1). Understand and improve the leadership practices of their IT managers; and 2). Determine the nature of the relationship between the business and IT communities. These objectives were in alignment with our proposed research project.

The objective of this project was not to refine any factor model, nor to develop another model of leadership. Our objective was to examine the current state of leadership practices in a large organisation that is seeking to exploit Information Technology. We wanted to relate these practices to organisational culture and understand its relationship to the history of the organisation with Information Technology, its expectation of that technology and its expectations of the technologists. We wanted to be the first to measure leadership style according to the 
established Full Range Leadership Model (FRLM) [BaAv97]. We wanted to improve the leadership practices of the IT managers. Finally, we wanted to see if a leadership culture could be created in the IT unit within the organisation and to track the effect of these improved leadership practices. These effects could be seen on the performance of the internal IT unit, the reported perceptions of leadership practices by the followers, the relationship between IT and the business communities and the alignment of IT and business activities. The industry partner was very happy to collaborate with us on this project.

We were able to gain access to confidential papers, all senior executives within the business, all directors of the IT unit, and all IT managers and staff within the organisation. In addition, the organisation was undergoing significant structural change and seeking to exploit Information Technology, both to improve business practice and for commercial gain.

Research in the real world must respond to changing environments. While undertaking this three-year research project, the IT unit was restructured three times. The entire organisation was restructured separately. There was a change of government and many of its key policies. New information systems were commissioned, old systems retired and packaged enterprise-wide software (SAP R/3) introduced. These changes have introduced noise in the research, as well as necessary shifts in study objectives.

\section{The Research Program}

This research project had three basic phases: 1). A Design phase, 2) An analysis of leadership beliefs and relationships, and 3). A study of actual leadership practice and leadership development.

During the design phase, a guiding conceptual framework was first developed based on a literature review and our experiences as consultants and academics. This was followed by detailed planning undertaken with the research partner together with a contextual analysis of the use of Information Technology by the organisation. This allowed the research team to be aware of the history and current use of IT within the organisation.

The leadership belief and relationship studies used qualitative methods to gather information. It gained commitment of senior managers to the total study through giving voice to their concerns. This sub-study involved all top business unit managers, all top IT executives and a representative sample of middle managers.

The leadership development sub-study commenced with determining current leadership practices through using the Multi-factor Leadership questionnaire, and developing an individual leadership development program based on the Full Range Leadership Model. 
This led to the research project having six embedded studies: 1) The IT Context Study, 2) The Implicit Leadership Belief Study, 3) The Business-IT Executive Relationship Study, 4) The Actual Leadership Practices Study, 5) The Individual Leadership Development Program, and 6) The Leadership Culture Development Program. We now summarise the purpose of each embedded study. The qualitative studies used the research method called phenomenography which focuses on identifying variations in experience or understanding of a phenomemon.

The IT Context Study (ITC) was to profile current and future IT within the organisation. It had the following objectives: 1). Profile IT usage, 2). Inventory current projects, projects under-development, 3). Assess the strategic impact of systems, and 4). Assess the vision of IT within the organization.

The Implicit Leadership Belief Study (ILB) was to determine the beliefs and expectations of leadership held by business and IT executives. It had the following objectives: 1). Develop means of characterising beliefs, 2). Detect variations in beliefs, 3). Develop qualitative Categories of Leadership beliefs and 4). Develop a graphical representation of Implicit beliefs and variations.

The Business-IT Executive Relationship Study (BITER) was to determine senior business manager expectations of IT management, IT manager expectations of Business management and variations in perceptions of the IT/Business relationship. It had the following objectives: 1). Create a description of expectations and beliefs and 2). Develop a graphical representation of expectations and beliefs.

The Actual Leadership Practices Study (ALPS) was to determine the benchmark of actual IT leadership practices using the MLQ. It had the following objectives: 1). Profile operant leadership styles, and 2). Determine if there existed any variations between IT sub-groups.

The Individual Leadership Development Program (ILDP) was to determine if a minimalist leadership intervention program has a measurable effect on reported leadership practices. It had the objective of changing the state of leadership practices as measured in a pre-test post-test experimental design using both quantitative measures (MLQ) and qualitative measures.

Finally, the Leadership Culture Development Program (LCDP) was to establish a leadership culture. It had the objective of creating a new, improved reflective leadership culture.

\section{Elements of Action Research in the Project}

There are three forms of action research: Scientific-technical, Participative and Emancipatory [Hu97]. Often the goal of an action research project will be to develop an improved process or product. This goal should be achieved, but accord- 
ing to [Ma95] it should lead to a secondary goal of personal improvement for all individual within the project. This is achieved through the process of reflection.

The focus of the project was to promote more effective practices, and the project did lead to personal involvement by the IT managers. We sought to improve leadership practices and the operant model that IT professionals had of their relationship with the business managers. This is more akin to the practical and deliberative approach of action research, rather than the scientific-technical approach [Hu97].

We were not out to solve immediate problems of Information Technology Management identified by this group. We sought to change the perceptions of this group of their responsibilities as leaders for their internal effectiveness and their external relationship quality. We sought to heighten their awareness of the centrality of relationship management and leadership practices in achieving organisational goals. In addition, we sought to show the IT management group how, by using effective leadership strategies, they could broaden the perception that business units held of the value of IT.

During the conduct of the study, we identified other issues in Information Technology Management which required attention. These included service delivery, adoption of standards and business resistance to such requirements, alignment of IT and business strategic planning, and retention of technical staff. These were issues that the IT directors were attending to, and not related to the focal research topic. We were interested in giving the collaborator a new understanding of their leadership practices and context. We were pleased when interim empirical evidence led to the directors becoming aware that a critical step to improve leadership practices was developing a clear, shared sense of purpose, mission and values.

The revelation of the pattern of responses in the Actual Leadership Practices survey was a critical incident - it engaged the interest of all IT participants. This outcome is the criteria demanded by [Gr82] for the study to be classified as emancipatory action research. We capitalised on the significance of these results by conducting a workshop on the Full Range Leadership Model with Bruce Avolio. This approach coupled with the desire by the directors to influence the business units to effectively exploit IT, led the directors to champion further activities leading to the creation of a leadership culture.

Our process of profiling leadership styles and subsequent presentation of the FRLM in which to evaluate existing practice led to the conclusion by all parties that significant change was required. [Ha72] refers to this stage as the organisation of enlightenment. The direction of required change was indicated by the results of the Multi-factor Leadership surveys. These revelations led to the research project becoming emancipatory, because the goal became to embed new values and management practices, as well as improve individual leadership practices. We were able to contrast existing practices with established theory. We sought to use 
that theory to explain the existence of identified problems and propose solution strategies to those problems. This shift in the purpose of the research project conforms to the two goals of emancipatory action research as described by [Hu97].

These results motivated executives to develop a retreat involving all senior IT managers and the directors. The goals of this retreat were to define the roles and responsibilities of each management layer so that these structures supported leadership practices, improved relations with the business, and moved the IT unit to become a strategic partner with the business units of the organisation. Strategies to achieve these goals were to be collaboratively developed, without regard for position within the organisational hierarchy.

Prior to this retreat, each individual was debriefed on his or her individual leadership style profile. An individual leadership development program was constructed that focused on one behaviour modification to be undertaken in the ensuing months. These individual debriefings on leadership practices led the individual to desire substantive change in both group and individual practices.

We used relevant theory to inform participants on potential alternative paths and to work with them to develop a solution strategy that fitted their organisational context. We engaged the individual in personal reflection on their role as leader, and as an agent for building better relationships with the business unit. Individuals were to keep a reflective log on their leadership practices and obstacles to successfully implementing the agreed leadership and management activities. The retreat acted as a vehicle for group reflection. This led to insights on the relationships between internal business units, the relationship of manager to director, the relationship between IT management and the business unit, and the relationship between the branches discharging the strategic vision of the division.

The directors were responsible for developing the conceptual structure of the retreat, and in leading its conduct. The researcher's role was not to force the relevant models and theories on the participants, but to clear blockages through summary and the use of anecdotes and analogies that would lead to the development of a shared vision and sense of purpose. This matches the demand by [Gr82] that the researcher (facilitator) 'not direct the outcome of the deliberative process by attempting to thrust enlightenment on the individuals, but must allow symmetrical communication to occur from which enlightenment will flow'.

Symmetric communication occurred formally in the conduct of the retreat and the debriefing sessions. The retreat provided a free flowing discussion leading to the development of the shared vision, without the under-pinning theories to cloud practical consideration and personal experience. Each session was closed by the researcher by reviewing the activities and outcomes and explaining their relationship to the FRLM or established IT Management practices. This articulation of these theories and strategies was designed to inform retreat participants of the context of their decisions, and to present additional options, rather than seek to ensure mastery of the relevant organising theory by these participants. Communica- 
tion also occurred informally through discussions with individuals during and after the retreat. It also occurred during discussions with the directors prior to and during the conduct of the retreat.

One obstacle experienced during the retreat, and experienced during the individual debriefings, were problems from the past. Participants continually sought to expose their grievances, or concerns with the past. We focused participants on the need to develop their future. This stage corresponds to what [Ha97] terms the organisation of action. This organisation of action seeks to establish critical theorems that will form the means to achieve the desired end state. Progressing to that end-state requires further reflection, measurement and application.

Retreat output included 1). A collective agreed vision of the purpose, mission and values of the ITRMU, 2). Agreed roles and responsibilities for directors and managers, 3). Agreed relationships and separation of duties between the directors and managers, 4). Statement of the type of relationship that the ITRMU sought to develop with its business partners, and 5). The set of competencies that would drive the function and management of the ITRMU.

The retreat closed with an affirmation of the derived strategies, a group commitment to further define the competencies and a commitment to provide mutual support in implementing the program. Formal follow-up group planning sessions were agreed. Branch level meetings were to be held that were to foster the development of the new practices and embed these into a new leadership culture.

\section{Conclusion}

The six embedded sub-studies were all essential in making the project emancipatory action research. These sub-studies allowed the participants to 1). understand the context of the problem from theory, 2). understand the context of the role of IT and the IT unit within the agency, 3). understand the relationships between the business and IT communities as a result of this history through the development of a descriptive model representing that relationship, 4). understand the implicit leadership models operating in the business and IT communities within the agency, 5). understand the actual leadership practices through the benchmarking studies in the ALPS project.

The outputs from these studies galvanized individuals and the IT management team collectively to seek improvements in their individual leadership practices, as well as to define a new culture and a way of working with business as a strategic partner.

The design of the study represents a tested methodology for emancipating IT leadership through an action research program. We suggest that this methodology is useful for understanding the richness inherent in studying Information Technology 
as a social system. This approach can be used in research into other aspects of IT management such as alignment, technology innovation and diffusion, and organisational effectiveness. As [Re99] states: (this approach can) articulate and offer democratic and emancipatory approaches to inquiry - relinquishing the monopoly of knowledge held traditionally by universities and other institutes of 'higher learning', and helping ordinary people regain the capacity to create their own knowledge in the service of their practical purposes. Thus, we can add relevance to rigour in our research to understand the organisational dynamics that constrain the exploitation of Information Technology by organisations and society at large.

\section{References}

[BaAv97] Bass, B.M. and Avolio, B.J.: Handbook of Multifactor Leadership Questionnaire California Consulting Psychologists 1997

[Gr82] Grundy, S.: Three Modes Of Action Research. as cited in Kemmis,S. and McTaggert,R. (eds) (1988). The Action Research Reader (3ed). Geelong: Deakin University Press 1982

[Ha74] Habermas, J.: Theory and Practice. Trans. J Viertal, London: Heinemann as cited in Three Modes Of Action Research in Kemmis,S. and McTaggert,R. (eds) (1988). The Action Research Reader (3ed). Geelong: Deakin University Press

[HoSc93] Holter, I.M., and Schwartz - Barcott,D.: Action Research: What is it? How has it been used and how can it be used in nursing? Journal of Advanced Nursing 1993:128; 298-304

[Hu97] Hughes, I.: Action Research Electronic Reader http://www.beh.cchs.usyd.edu.au/ arow/Reader/rintro.htm 1997

[Ma95] Masters, J. The History of Action Research in Hughes, I. (1997) Action Research Electronic Reader http://www.beh.cchs.usyd.edu.au/ arow/Reader/rintro.htm 1995

[Re99] Reason, P.: Integrating Action and Reflection through Co-operative Inquiry Management Learning vol 30(2) 1999 pp 207-226. 